\title{
Geostatistical Modelling and Mapping of the Concentration of Gaseous Pollutants
}

\author{
Okpoko J. S. ${ }^{1}$ and Audu H. A. P. ${ }^{2, *}$ \\ ${ }^{1,2}$ Department of Civil Engineering, Faculty of Engineering, University of Benin, Benin City, Edo State, Nigeria \\ Corresponding Author: *henry.audu@ uniben.edu
}

\begin{abstract}
In this study, the prediction of the concentration of gaseous pollutants around Ughelli West gas flow station in Delta State of Nigeria was carried out using Geostatistical technique in GIS environment. Since air pollutants negatively affect quality of air, lives and the environment, there is therefore the need to frequently monitor air quality, have thorough understanding of the pollutants' concentration and their spatial distribution in an environment. The gaseous pollutants data of volatile organic compounds (VOCs), methane $\left(\mathrm{CH}_{4}\right)$, nitrogen dioxide $\left(\mathrm{NO}_{2}\right)$, sulphur dioxide $\left(\mathrm{SO}_{2}\right)$ and ozone $\left(\mathrm{O}_{3}\right)$, were obtained using Multi-parameter gas monitor while that of fine particulate matter $\left(P M_{2.5}\right)$ was obtained with SPM meter for a period of three months. Thermo Anemometer was used to obtain the values of wind speed, ambient temperature, atmospheric pressure and relative humidity. Artificial Neural Network designer software (Pythia) was used to validate the acquired field data; predict the concentration of the gaseous pollutants at selected distances from the flow station. The geospatial coordinates of the flow station were obtained using Global Navigation Satellite System (GNSS) receivers; the geospatial modelling and analysis were performed with ArcGIS software and ordinary kriging method of Geostatistical techniques. The results of the maximum concentration for the gaseous pollutants in the study area were 28.17 $\mu \mathrm{g} / \mathrm{m}^{3}, 19.44 \mu \mathrm{g} / \mathrm{m}^{3}, 0.37 \mu \mathrm{g} / \mathrm{m}^{3}, 49.81 \mu \mathrm{g} / \mathrm{m}^{3}, 0.061 \mu \mathrm{g} / \mathrm{m}^{3}$ and $0.047 \mu \mathrm{g} / \mathrm{m}^{3}$ for VOCs, $\mathrm{CH}_{4}, \mathrm{NO}_{2}$, $\mathrm{PM}_{2.5}, \mathrm{O}_{3}$ and $\mathrm{SO}_{2}$ respectively. The root mean square error for the concentration of the gaseous pollutants, ozone and sulphur (IV) oxide in the study area were 0.01618 and 0.008417 indicating a good interpolation model, while their root mean square standard errors, which show the reliability of the predicted values, were 0.70513551 and 0.8459251 respectively. These results conform with the report of other researchers that a better kriging method yields a smaller root mean square and a standard root mean square closer to one. The developed prediction maps for the gaseous pollutants in this study revealed that the study area will experience lower concentration of gaseous pollutants at a distance of $400 \mathrm{~m}$ and above.
\end{abstract}

Keywords: Gaseous pollutants, Spatial interpolation, Geostatistical mapping, Kriging, Modelling

\subsection{Introduction}

Air pollution is the contamination of the atmosphere by gaseous, liquid or solid wastes or their byproducts, including noise present in the atmosphere in concentrations that can endanger human health and the health and welfare of plants and animals, or can attack materials, reduce visibility, or produce undesirable odour (Khitoliya, 2007). Air pollution is a major problem with strong impact on the environment (Clark et al., 2016), economy (Carleton and Hsiang, 2016) and human health (Lelieveld et al., 2015).

Gaseous pollutants from burning of fossil fuels such as gas, oil, coal and wood affect the earth, buildings, water and air, resulting in fog, smog and global warming, which deteriorate vegetation, forests, and even human health (Obahiagbon, 2002; Khitoliya, 2007; Rai et al., 2011). Gas flaring is one of the most challenging energy and environmental problems facing the world today, a local environmental catastrophe and a global energy and environmental problem which have persisted for decades (Ismail and Umukoro, 2012). Gas flaring in the study area of the Niger Delta Area of Nigeria 
degrades soil, makes it poor and infertile for crop production; excessive heat from the flare kills or scares away most of the micro- and macro-organisms that would have helped to improve the soil fertility through further breaking down of the soil particles, further decaying and decomposition of the organic matters of the soil (Odjugo and Osemwenkhae, 2009). Gas flaring contributes to the emission of toxic gases such as carbon monoxide, nitrogen dioxide, sulphur dioxide and methane (Orubu, 2002; Ite and Udo, 2013). Gas flares damage vegetation, economic crops and the environment; contaminate surface and ground water, corrode roofing sheets, monuments and structures through acidification of rain water (Olabaniyi and Efe, 2007; Akpoborie et al., 2000; Oghifo, 2011).

Nigeria flares 17.2 billion $\mathrm{m}^{3}$ of natural gas per year from crude oil exploration in the Niger Delta area which is approximately one quarter of the current power consumption of the African continent. This contributes to climate change which has serious implications for both Nigeria and the rest of the world (Ajugwo, 2013). There is therefore a need to predict the level of gaseous pollutants concentration and the spread of gaseous pollutants from the activities of Ughelli West flow station so as to know at what distance from the flare point the pollution effect will be minimal.

Dispersion modelling is undertaken in order to predict the concentration and spread of pollutants (Anjaneyuhu et al., 2011). Yannawar et al. (2014) opined that dispersion models are used to predict the fate of pollutants after they are released into the atmosphere. The goal of air quality dispersion modelling is to estimate a pollutant's concentration at a point downwind of one or more emission sources (Narayanan, 2009).

The aim of this study is to carry out the geostatistical dispersion modelling and mapping of the gaseous pollutants emitted from Ughelli West Gas flow station and determine their level of concentration in the environment of the study area. The objectives of the study therefore are to: determine the gaseous pollutants with their concentrations which are emitted from Ughelli West flow station; develop a geo-statistical dispersion model, using kriging method, a geostatistical technique for spatial interpolation with ArcGIS software and produce a prediction map of the un-sampled location showing the spread of monitored gaseous pollutants as well as determine the distance where the effect of the gaseous pollutants was minimal.

\subsection{Spatial interpolation, Geostatistical techniques and modelling}

\section{a) Spatial interpolation}

The earth's surface is one type of surface that most professionals in the Construction industry inter alia are familiar with. Nowadays, due to technological advancement, there is another type of surface used in GIS environment, which cannot be seen physically but can be visualized in the same way as the land surface. It is the statistical surface and some of its examples are precipitation, population density, water table and snow accumulation. Constructing a statistical surface is similar to that of the land surface except that the input data are typically limited to a sample of point data. A process of filling in data between the sample points is therefore required (Chang, 2014). Spatial interpolation refers to the process of using points with known values to estimate values at other unknown points. Through spatial interpolation, the precipitation value at a location with no recorded data can be predicted by using known readings at nearby weather stations. Spatial interpolation is therefore a means of creating surface data from sample points so that the surface data can be displayed as a three dimensional (3-D) surface and also used for modelling and analysis. The two basic inputs required in spatial interpolation are the known points, also called the control points, sample points or observation points (which are actual points such as weather stations or survey sites) and an interpolation method. The control points provide the necessary data for developing an interpolator (e.g. a mathematical equation) for spatial interpolation. The number and distribution of control points can greatly influence the accuracy of spatial interpolation.

The first spatial interpolation methods can be grouped into global and local interpolation methods. The second spatial interpolation methods can be classified into exact and inexact interpolation while the third spatial interpolation methods can also be grouped as deterministic and stochastic interpolation. The global interpolation method uses every available known points to estimate an unknown value; it's designed to capture the general trends of the surface, include trend surface 
models and regression models while the local interpolation method uses a sample of known points to estimate an unknown value; it's designed for the local or short-ranged variation and required much less computation than a global interpolation method. The exact interpolation predicts a value at the point location that is the same as its known value. It generates a surface that passes through the control points. The inexact interpolation or approximate interpolation predicts a value at the point location that differs from its known value. The deterministic interpolation provides no assessment error with predicted values, while the stochastic interpolation considers the presence of some randomness in its variables and offers assessment of prediction errors with estimated variances (Chang, 2014).

Davis (1986) together with Bailey and Gatrell (1995) reported that for an inexact interpolation method, the trend surface analysis approximates points with known values using a polynomial equation (interpolator). This polynomial equation can then be used to estimate values at the other points. A linear or first-order trend surface model, which can be used to approximate inclined plane surfaces and has three coefficients, uses the following equation (Chang, 2014):

$$
Z_{x y=} b_{0+} b_{1 x+} b_{2 y}
$$

where,

$x$ and $y \quad$ known coordinates of the points.

$z \quad$ function of $x$ and $y$ coordinates

$b_{0}, b_{1}, b_{2} \quad$ coefficients estimated from the known coordinates.

The "goodness of fit" of trend surface model in Equation 1 can be measured and tested since it is computed by least square method. Besides, the deviation or residual between the observed and the estimated values can be computed for each known point.

Complex surfaces require higher-order trend surface models and more computation than a lower-order trend surface model. A cubic or third-order trend surface model such as hills and valleys, etc. which requires estimation of 10 coefficients is based on the following equation (Chang, 2014):

$$
Z_{x y=} b_{0+} b_{1 x+} b_{2 y+} b_{3 x^{2}+} b_{4 x y+} b_{5 y^{5}+} b_{6 x^{3}+} b_{7 x^{2} y+} b_{8 x y^{2}+} b_{9 y^{3}}
$$

where,

$x$ and $\mathrm{y}$

$b_{0}, b_{1}, b_{2}, b_{3}, b_{4}, b_{5}, b_{6}, b_{7}, b_{8}, b_{9}$

known coordinates of the points

coefficients estimated from the known coordinates.

A GIS package offer up to $12^{\text {th }}$-order trend surface models. Coordinates are the most used method for describing the horizontal positions of points and features on the earth's surface. A GIS software has many options of coordinate systems. A coordinate system is a method for identifying the location of a point on the earth's surface. Decimal degrees system is a measuring system for geographical coordinates (longitudes and latitudes) expressed in degrees. Universal Transverse Mercator (UTM) system is a coordinate system that divides the earth's surface between $84^{\circ} \mathrm{N}$ and $80^{\circ} \mathrm{S}$ into 60 zones, with each further divided into the Northern hemisphere and the Southern hemisphere (McCormac, 2004; Chang, 2014).

\section{b) Geostatistical Techniques and modelling}

Geostatistics is a class of statistics used to analyze and predict the values associated with spatial or spatiotemporal phenomena. It incorporates the spatial (and in some cases temporal) coordinates of the data within the analyses. Many geostatistical tools were originally developed as a practical means to describe spatial patterns and interpolate values for locations where samples were not taken. Those tools and methods have since evolved not only to provide interpolated values, but also measures the uncertainty for those values. The measurement of uncertainty is critical to informed decision making, as it provides information on the possible values (outcomes) for each location rather than just one interpolated value (ESRI-ArcGIS manual). Geostatistics is then used to produce predictions (and related measures of uncertainty of the predictions) for the unsampled locations. Geostatistics is widely used in many areas of science and engineering, for example: In the environmental sciences, 
geostatistics is used to estimate pollutant levels in order to decide if they pose a threat to environmental or human health and warrant remediation (ESRI-ArcGIS manual). Geostatistical analysis has also evolved from uni-to multivariate and offers mechanisms to incorporate secondary datasets that complement a (possibly sparse) primary variable of interest, thus allowing the construction of more accurate interpolation and uncertainty models. These models can be applied to a wide variety of scenarios and are typically used to generate predictions for unsampled locations, as well as measures of uncertainty for those predictions.

Geostatistical techniques assume that at least some of the spatial variation observed in natural phenomena can be modelled by random processes with spatial autocorrelation and require that the spatial autocorrelation be explicitly modelled. Geostatistical techniques can be used to describe and model spatial patterns (variography), predict values at unmeasured locations (kriging), and assess the uncertainty associated with a predicted value at the unmeasured locations (kriging). The Geostatistical Wizard offers several types of kriging, which are suitable for different types of data and have different underlying assumptions: ordinary, simple, universal, indicator, probability, disjunctive, areal interpolation and empirical Bayesian.

Kriging, a geostatistical method for spatial interpolation, differs from other local interpolation methods because it can assess the quality of prediction with estimated prediction errors. Kriging has since been adopted in a wide variety of disciplines. In GIS environment, kriging has also become a popular method for converting light detection and ranging (LIDAR) point data into DEM (Zhang et al., 2003). The digital representation of topography (the shape, configuration, relief, roughness, three- dimensional quality of the earth's surface) is referred to as digital elevation model (DEM) (McCormac, 2004).

Kriging assumes that the spatial variation of an attribute is neither totally random (stochastic) nor deterministic. Instead the spatial variation may consist of three components, namely: a spatially correlated component (representing the variation of the regional variable; a drift or structure (representing a trend) and a random error term. The interpretation of these components has led to the development of different kriging methods for spatial interpolation. Kriging uses semi-variance to measure spatially correlated component (also called spatial dependence or spatial autocorrelation). The semi-variance is expressed mathematically as (Chang, 2014):

$\gamma(\mathrm{h})=\frac{1}{2}\left[\mathrm{z}\left(x_{i}\right) \mathrm{z}\left(x_{j}\right)\right]^{2}$

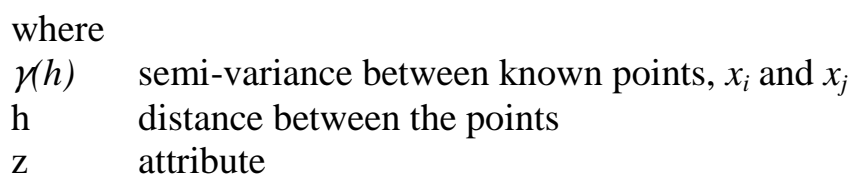

If spatial dependence does not exist in a data set, known points that are close to each other are expected to have small semi-variances, and known points that are farther apart are expected to have larger semi-variances. In other words, the semi-variance is expected to increase as the distance increases in the presence of spatial dependence.

A semi-variogram is used as measure of spatial autocorrelation in the data set. When it's used as an interpolator in kriging, it must be fitted with a mathematical function or model. The fitted semivariogram can then be used for estimating the semi-variance at any given distance. Webster and Oliver (2001) opined that fitting a model to a semi-variogram is a difficult task in geostatistics because of the number of models to choose from. When the kriging method is ordinary, the available models are spherical, circular, exponential, Gaussian, and linear, whereas in universal Kriging, the available models are linear with linear drift and linear with quadratic drift. Kriging attempts to minimize the error variance and set the mean of the prediction errors to zero so that there is no overor under-estimates. Geostatistical Analyst extension to ArcGIS offers eleven (11) models. 
As regards the procedure for comparing the models, Webster and Oliver (2001) recommend a procedure that combines visual inspection and cross-validation. Cross-validation is a method for comparing interpolation methods. Jarvis et al. (2003) propose the use of artificially intelligent system for selecting an appropriate interpolator based on task-related knowledge and data characteristics. Two common models for fitting semi-variograms are the spherical and exponential. A spherical model shows a progressive decrease of spatial dependence until some distance, beyond which the spatial dependence levels off.

An exponential model exhibits a less gradual pattern than a spherical model. The spatial dependence decreases exponentially with increasing distance and disappear completely at an infinite distance. A fitted semi-variogram has three elements, viz: nugget, range and sill. The nugget is the semi-variance at the distance of zero (0), representing measurement error, or microscale variation or both. The range is the distance at which the semi-variance starts to level off. In other words, the range corresponds to the spatially correlated portion of the semi-variogram. Beyond the range, the semi-variance becomes a relatively constant value. The semi-variance at which the levelling takes place is called sill. Assuming the absence of a drift, ordinary kriging focuses on the spatially correlated component and uses the fitted semi-variogram directly for interpolation. The general equation for estimating the $\mathrm{Z}$ value at a point for ordinary kriging is:

$Z_{0}=\sum_{i=1}^{s} Z_{x} W_{x}$

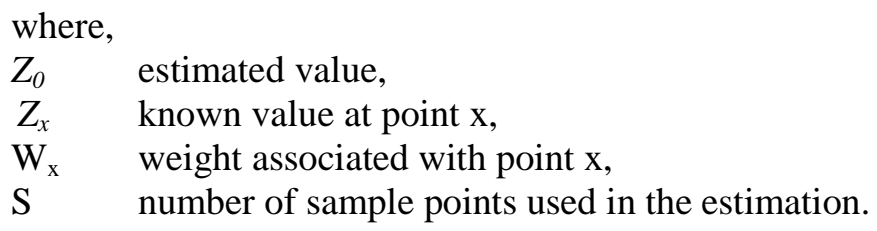

The weights can be derived from solving a set of simultaneous equations.

\subsection{Methodology}

\subsection{Study area}

The study area is located at Ughelli West oil and gas plant flow station of Delta State of Nigeria. Ughelli West facility is very strategic and supplies more than 80percent of gas used in Nigeria. It is the number one gas processing plant in the whole of West Africa (SPDC, 2000). Ughelli West oil field, which is situated at the Oil Mining Lease (OML) 34 in Delta State of the Niger Delta Region, is about $20 \mathrm{~km}$ South East of Warri and $7 \mathrm{~km}$ to the South of Ughelli West field. The facility is bounded by three communities namely Otu -Jeremi, Otor - Udu and Iwhreka communities. It produces an average of $205 \mathrm{mmscf}$ of gas daily (an equivalent of 786MW of electricity). The map of Delta State showing the position of OML34 and the map of OML34 showing the location of Ughelli West Gas Plant are shown in Figures 1 and 2 respectively.

\subsection{Data acquisition, processing and Geostatistical analysis}

The study involved prediction of the level of concentration of gaseous pollutants from Ughelli West flow station, and it was carried out using the following steps: data acquisition and processing; determination of the gaseous pollutants as well as their level of concentration which were emitted from the study area; Geo-statistical analysis of the data. 


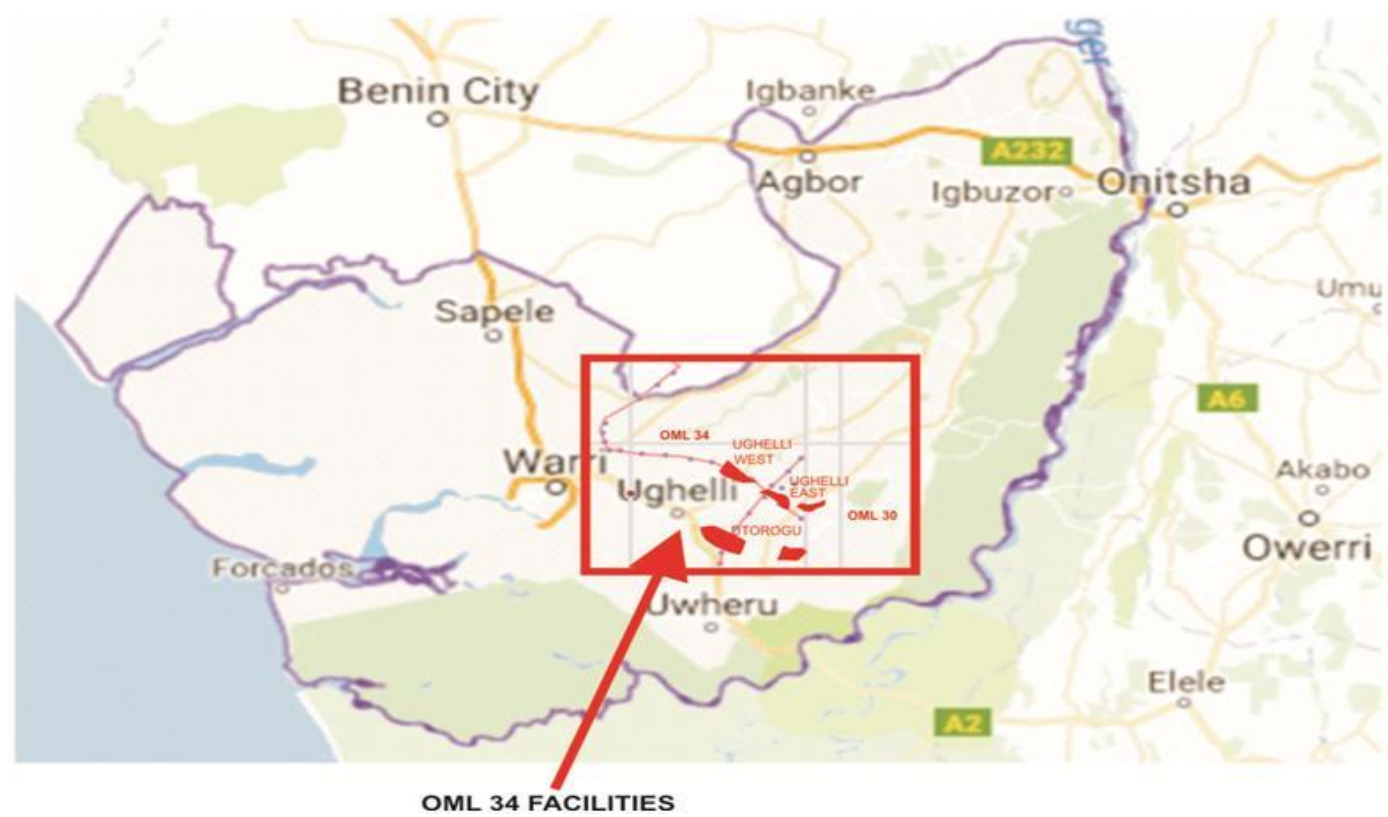

Figure 1: Map of Delta State showing the position of OML34 (Source: SPDC, 2000)

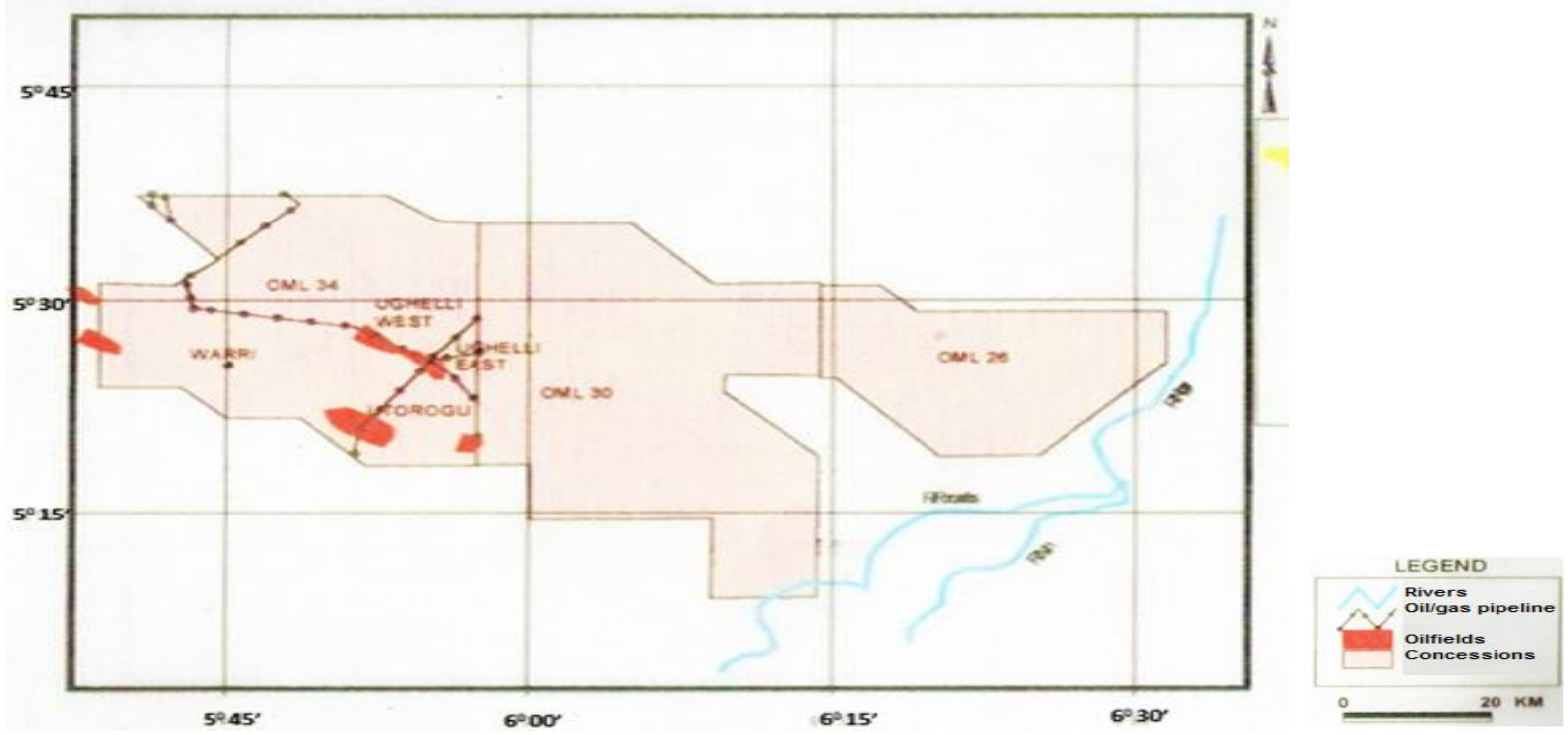

Figure 2: Map of OML 34 showing location of Ughelli West Gas Plant (Source: SPDC, 2000)

\subsubsection{Data acquisition and processing}

In this study, the gaseous pollutants in the study area are volatile organic compounds (VOCs), methane $\left(\mathrm{CH}_{4}\right)$, nitrogen dioxide $\left(\mathrm{NO}_{2}\right)$, fine particulate matter $\left(\mathrm{PM}_{2.5}\right)$, ozone $\left(\mathrm{O}_{3}\right)$ and sulphur dioxide $\left(\mathrm{SO}_{2}\right)$. They were monitored on daily basis for a period three months, from September to November. The data were transformed into weekly maximum concentration in accordance with Directorate of Petroleum Resources (DPR) standards (EGASPIN, 2002). The monitoring points were established in line with Environmental Guidelines and Standards for the Petroleum Industry in Nigeria (EGASPIN) and the range of measurement was $60 \mathrm{~m}$ to $500 \mathrm{~m}$, using spacing distances of $60 \mathrm{~m}, 80 \mathrm{~m}$, $100 \mathrm{~m}, 150 \mathrm{~m}, 200 \mathrm{~m}, 250 \mathrm{~m}, 300 \mathrm{~m}, 350 \mathrm{~m}, 400 \mathrm{~m}, 450 \mathrm{~m}$ and $500 \mathrm{~m}$ from the flare point (EGASPIN, 2002). The standard gaseous pollutants monitoring equipment, namely: Gas monitor, SPM meter, Anemometer and GNSS receivers were calibrated, tested and confirmed to be in good working conditions and were therefore used for this study. Aeroqual multi-parameter environmental monitor (series 500) was employed to monitor the concentrations of volatile organic compounds (VOCs), oxides of nitrogen $\left(\mathrm{NO}_{2}\right)$, oxides of sulphur $\left(\mathrm{SO}_{2}\right)$, ozone $\left(\mathrm{O}_{3}\right)$ and methane $\left(\mathrm{CH}_{4}\right)$. Aerocet-531 SPM meter was used to monitor the concentration of particulate matter $\left(\mathrm{PM}_{2.5}\right)$, while Sky master thermo anemometer (SM-28) was used to obtain the important climatic variables such as wind speed, 
atmospheric pressure, ambient temperature and relative humidity, which affect the dispersion of gaseous pollutants.

The maximum concentration of the pollutants at each sampling point within the entire period of experimentation was selected for the modelling; extreme value statistics was carried out using the data analysis tool pack of Microsoft Excel software. The Global Navigational Satellite System (GNSS) receivers were used to obtain the geographical coordinates at each monitoring point in the study area. The coordinates were converted to decimal degrees format and the results presented in grid UTM coordinates. The field data were validated using artificial neural network (ANN) designer software (Pythia) in order to evaluate the adequacy of the field data for use in the modelling of the gaseous pollutants. Using the training data, Pythia employed the evolutionary optimizer to search the neural network topology that best understands the input and output data presented for training. During the training phase, the actual output of the network was compared with the experimental output and the error propagated back towards the input of the network. The condition for the best performance, evolutionary optimization for selecting best network topology and the optimum neural network of the architecture for Ughelli West flow station were determined. Using the optimum neural network, the repro pattern set function of the pythia program was activated to predict the pollutant concentration based on the input and field output of the Ughelli West gas flow station.

\subsubsection{Geo-statistical analysis of the data}

One of the unique features of spatial analysis is the development of a prediction map which allows for the determination of the concentration of gaseous pollutants in unsampled location. In order to understand the dispersion and spatial variation of the pollutants with sampling points around the study area, a geospatial modelling using ArcGIS software and ordinary kriging technique was used to interpolate the gaseous pollutants values at the unknown locations. The objectives of this study, the understanding of the phenomenon (gaseous pollutants) and the required output of the interpolation model were the factors that determine the choice of the geostatistical tehnnique (ordinary kriging) used for this study.

Detailed geo-statistical analysis of the data acquired from Ughelli West flow station was carried out. The input parameters for the geostatistical modelling are the rectangular coordinates of each sampling point which include: Northings, Eastings and the Elevations in addition to the concentrations of the gaseous pollutants investigated, which are the attribute data. To perform the geospatial analysis of the toxic gaseous pollutants, ordinary kriging method of geostatistical interpolation techniques was employed in this study because of its abilities of modelling and producing maps of kriging: predicted values, standard errors associated with the predicted values. The kriging weights were obtained from fitting of semi-variogram models developed by viewing the spatial structure of the data.

The basic steps involved in the application of kriging interpolation method include:- generation of coordinates and the attribute data; fitting of semi-variogram/covariance model; generation of cross validation statistics for assessing model performance and production of prediction map(the output of the variables being modelled) which shows the spatial distribution of each specific pollutant.

\subsection{Results and Discussion}

\subsection{Predicted pollutant concentration for Ughelli West Flow Station using Pythia software}

The input parameters (acquired field data) and the output parameters used for the network training with Pythia Neural net software for the study area (Ughelli West Flow Station) are presented in Table 1. The input parameters in Table 1 were selected in this study since they form the bedrock of the critical climatic variables that affect the geostatistical dispersion of gaseous pollutants in the study area. The results of Pythia predicted (net) gaseous pollutants concentrations at Ughelli West gas flow station, shown in Table 1, are in close agreement with the obtained field output values indicating that the field data were accurate and reliable. 
Table 1: Predicted pollutant concentration for Ughelli West Flow Station using Pythia software

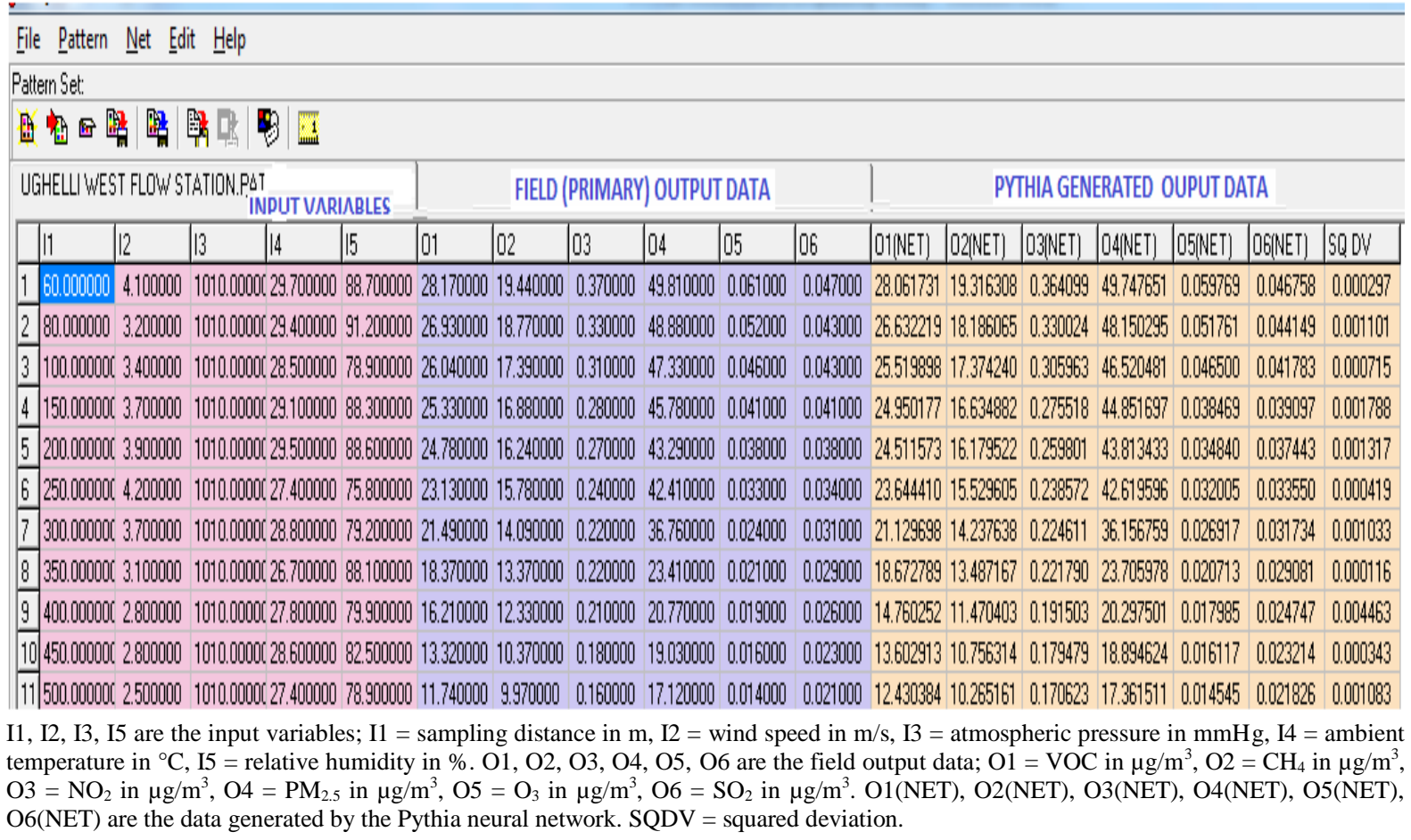

3.2. Results and discussion on some vital geostatistical modelling for the spatial distribution of the maximum concentration of ozone $\left(\mathrm{O}_{3}\right)$ and sulphur (iv) oxide $\left(\mathrm{SO}_{2}\right)$ around Ughelli West Flow Station

The different stages of kriging modelling required for building geostatistical model for the spatial distribution of maximum concentration of ozone and sulphur (iv) oxide around Ughelli West flow station are presented in Figures 3 to 8 . Figures 3 and 4 show the first modelling step which describes the modelling technique (kriging) employed to perform the geospatial modelling of maximum concentration of Ozone and sulphur (iv) oxide around the flow station respectively. They contain the choice of the method, which is ordinary kriging /cokriging method and the input data, which is the maximum concentration of the gaseous pollutants: ozone and sulphur (iv) oxide, in Ughelli West flow station.

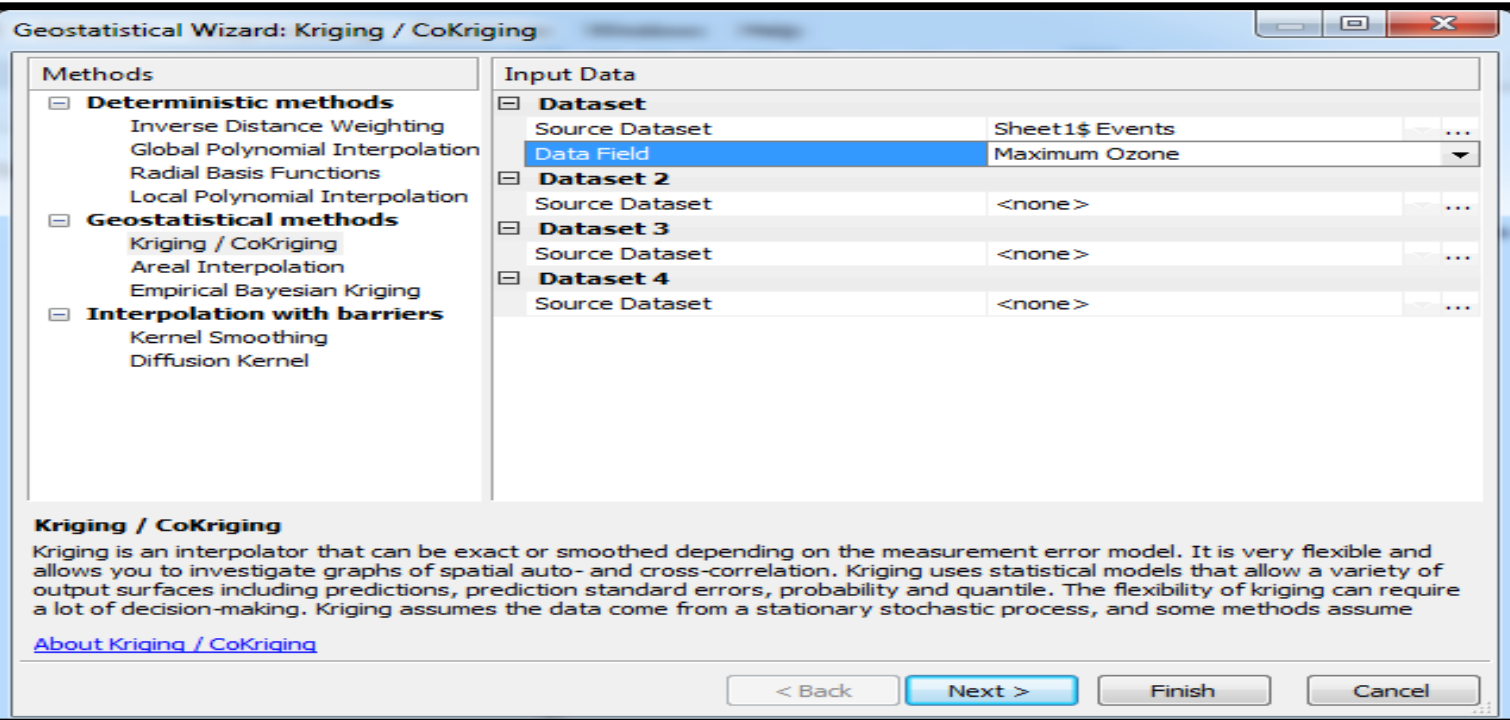

Figure 3: Kriging modelling of ozone around Ughelli West flow station 


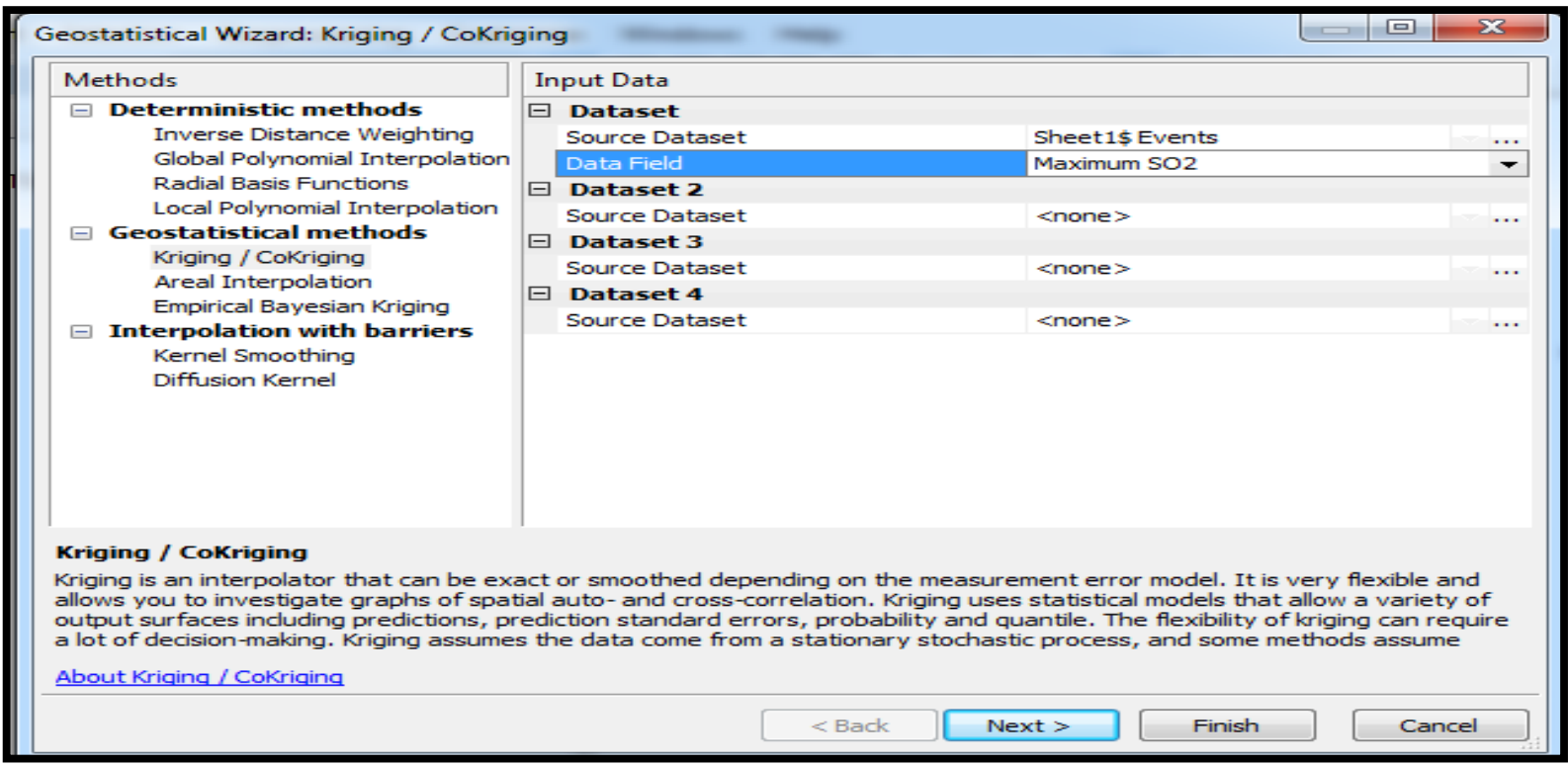

Figure 4: Kriging modelling of sulphur (iv) oxide around Ughelli West flow station

Ordinary kriging method, which is the default interpolation method in the ArcGIS environment and the most flexible method of interpolation, provides better correlation between the input variables and the corresponding output variables. It also considered both the distance and the degree of variation between known data points when estimating values in unknown areas. It is a robust interpolation tool which derives weights from surrounding measured values to predict values at unmeasured locations.

The Semi-variogram/Covariance models for spatial distribution of ozone and sulphur (iv) oxide around Ughelli West flow station are presented in Figures 5 and 6 respectively. The semivariogram/covariance model in Figures 5 and 6 enabled the spatial relationships between measured points in the study area to be examined and to explore the assumption that points that are closer together are more alike than those that are farther apart. The process of fitting a semi-variogram model to capture the spatial relationships in the data is often known as variography. The cross hairs show the locations that have no measured values. The values at the measured locations were used to predict the values at the crosshairs. The red points have more influence on the values of the unknown locations since they are closer to the location to be predicted.

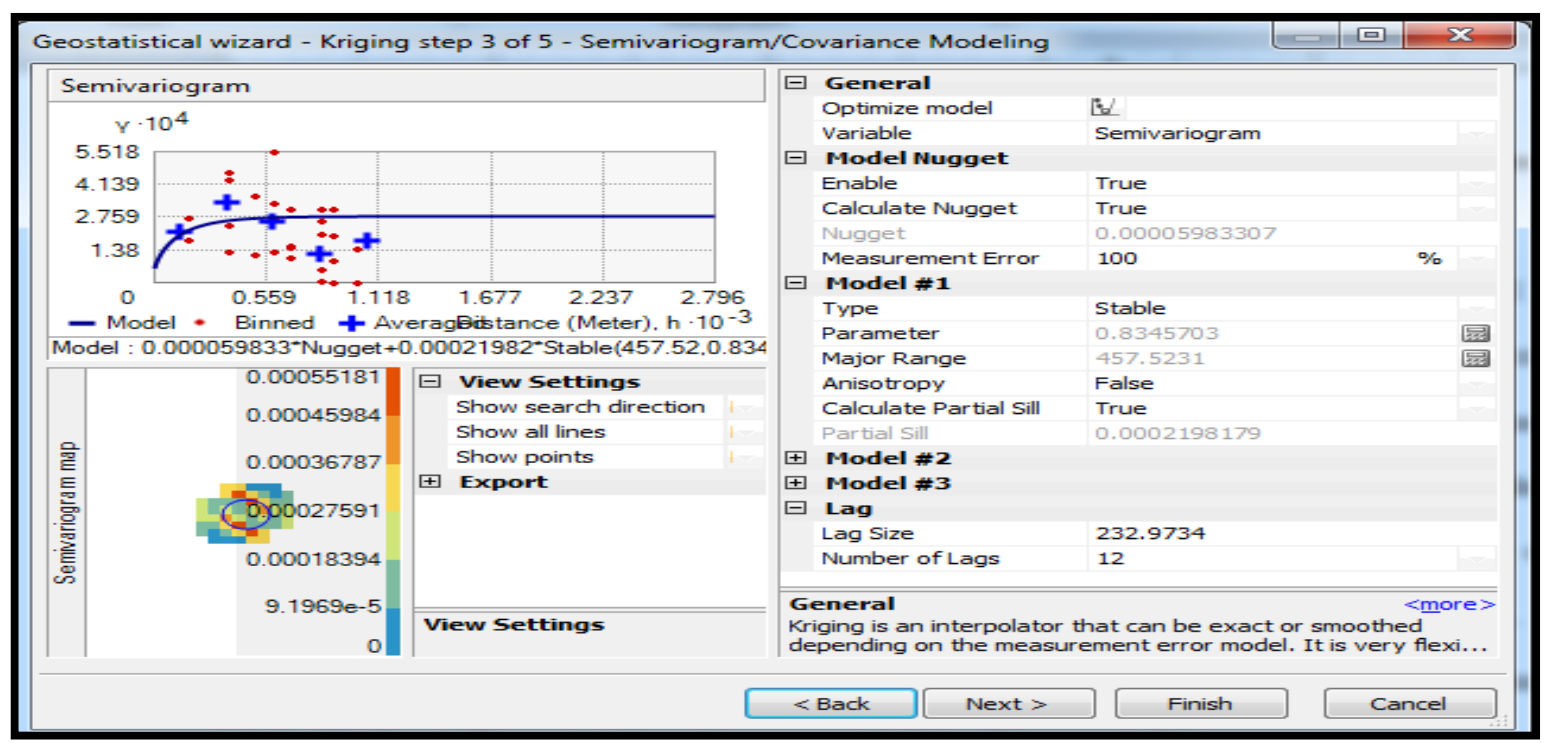

Figure 5: Semi-variogram model for the spatial distribution of ozone around the study area 


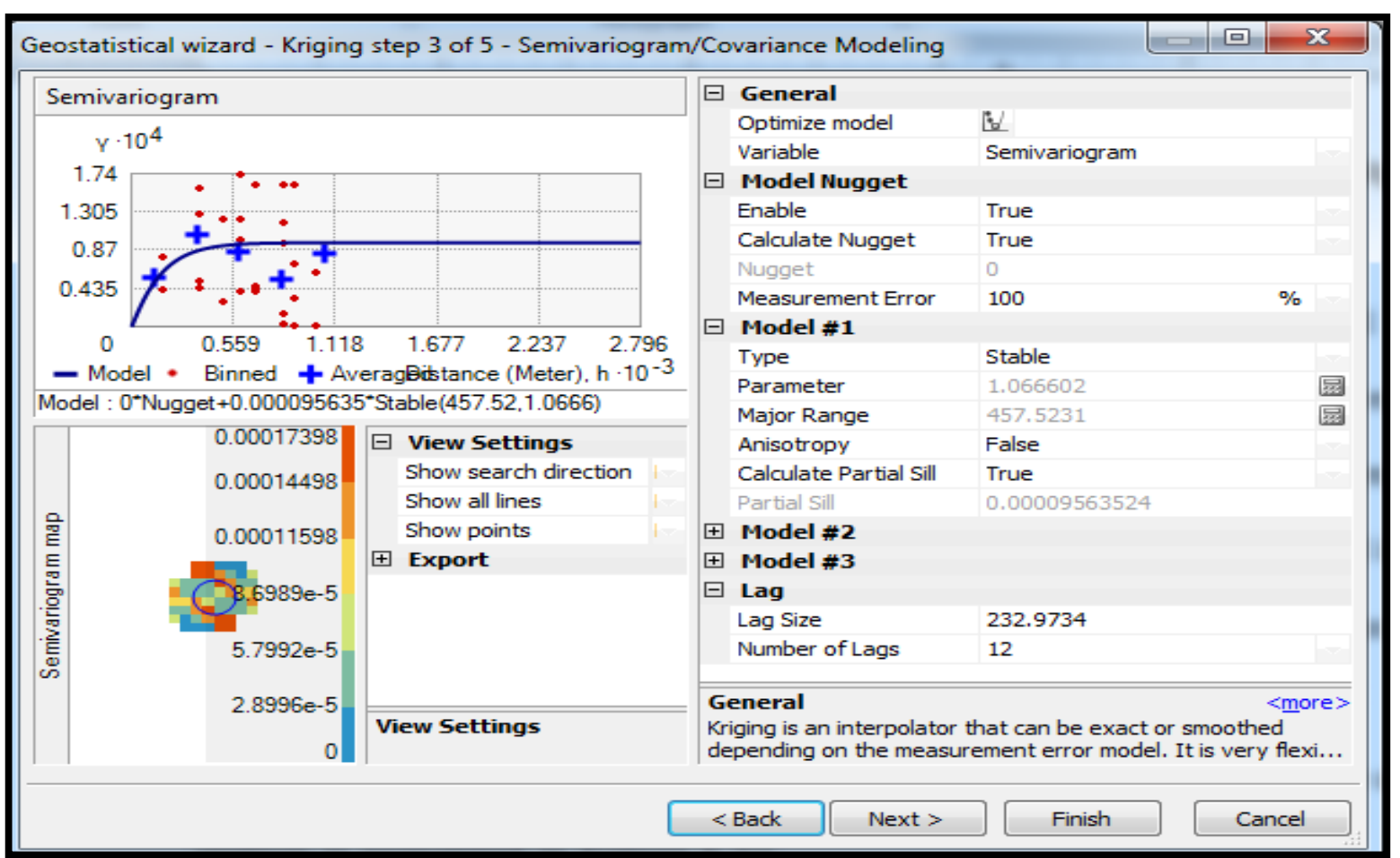

Figure 6: Semi-variogram model for the spatial distribution of sulphur (iv) oxide

The cross validation statistics of the gaseous pollutants, Ozone and sulphur (iv) oxide, and their spatial distribution around Ughelli West flow station are shown in Figures 7 and 8 respectively. Both figures give an idea of how well the models predict the concentration of ozone and sulphur (iv) oxide at the unknown locations in the study area. In Figure 7, the root mean square standard error was 0.8459251 while the average standard error value(the root mean square) which represents the absolute difference between the measured concentration of ozone and the predicted concentration of ozone gave a value of 0.01618 as observed in Figure 7, indicating a good interpolation model prediction for the prediction of the concentration of ozone around Ughelli West flow station. The root mean square, a common measure of accuracy, quantifies the differences betweeen the known and the predicted values at the unknown sample points. In Figure 8, the root mean square standard error was 0.70513551 . The average standard error value which represents the absolute difference between the measured concentration of sulphur (iv) oxide and the predicted concentration of sulphur (iv) oxide gave a value of 0.008417 indicating a good interpolation model for the prediction of the concentration of sulphur (iv) oxide around Ughelli West flow station. These root mean square standard errors for the ozone and sulphur (iv) oxide around Ughelli West flow station are measures of uncertainty for these predictions and show the reliability of the predicted values. These results, which are the diagnostic statistics(root mean square error and the standard root mean square error) for ozone and sulphur (iv) oxide conform with the report of Chang (2014) that a better kriging method yields a smaller root mean square, and a standard root mean square closer to one(1). 


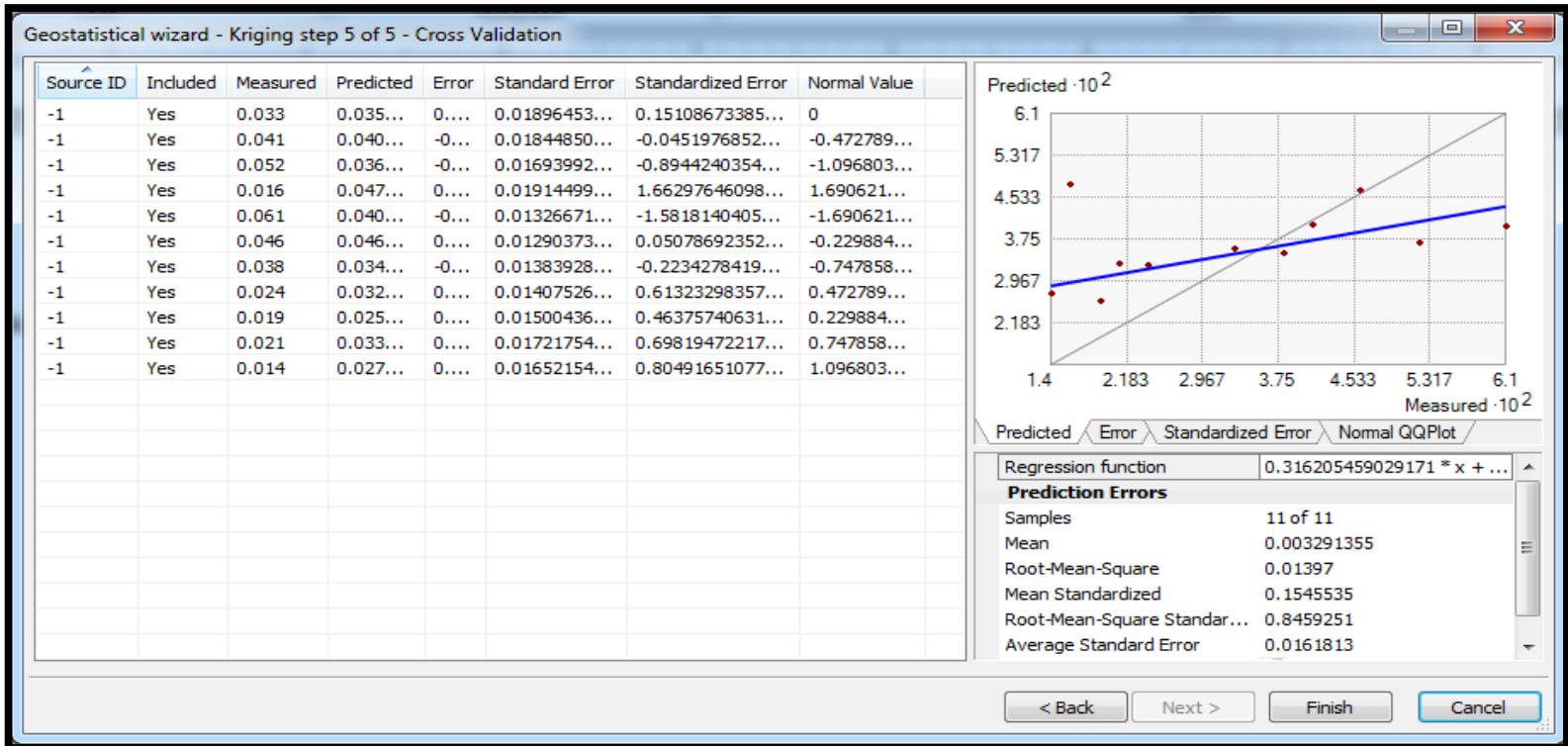

Figure 7: Cross validation statistics of gaseous pollutant(ozone) distribution in Ughelli West Flow Station

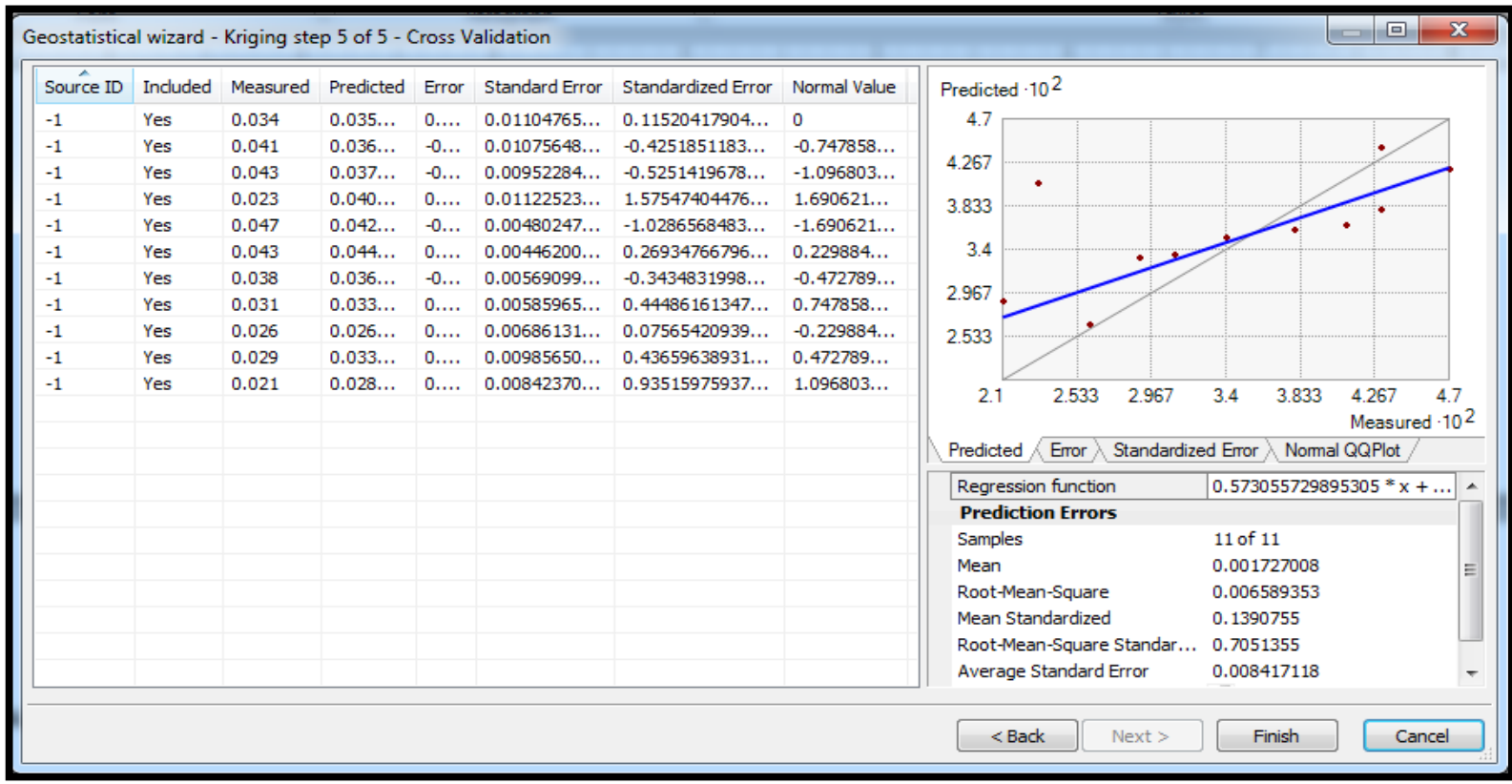

Figure 8: Cross validation statistics of sulphur (iv) oxide distribution in Ughelli West Flow Station

\subsection{Prediction maps for spatial distribution of ozone and sulphur (iv) oxide around Ughelli West flow station}

The prediction maps which show the spatial distribution of ozone and sulphur (iv) oxide around Ughelli West flow station are presented in Figures 9 and 10 respectively. It is seen from the prediction map of Figure 9 that areas with light brown and lemon colour will experience lower concentration of ozone while areas with purple and red colour will experience higher concentration of ozone. It is seen from the prediction map of Figure 10 that areas with light brown and grey colour will experience lower concentration of sulphur (iv) oxide while areas with purple and red colour will experience higher concentration of sulphur (iv) oxide. Besides, The prediction maps showed that from $400 \mathrm{~m}$ and above the gaseous pollutants concentrations experience reduction. 


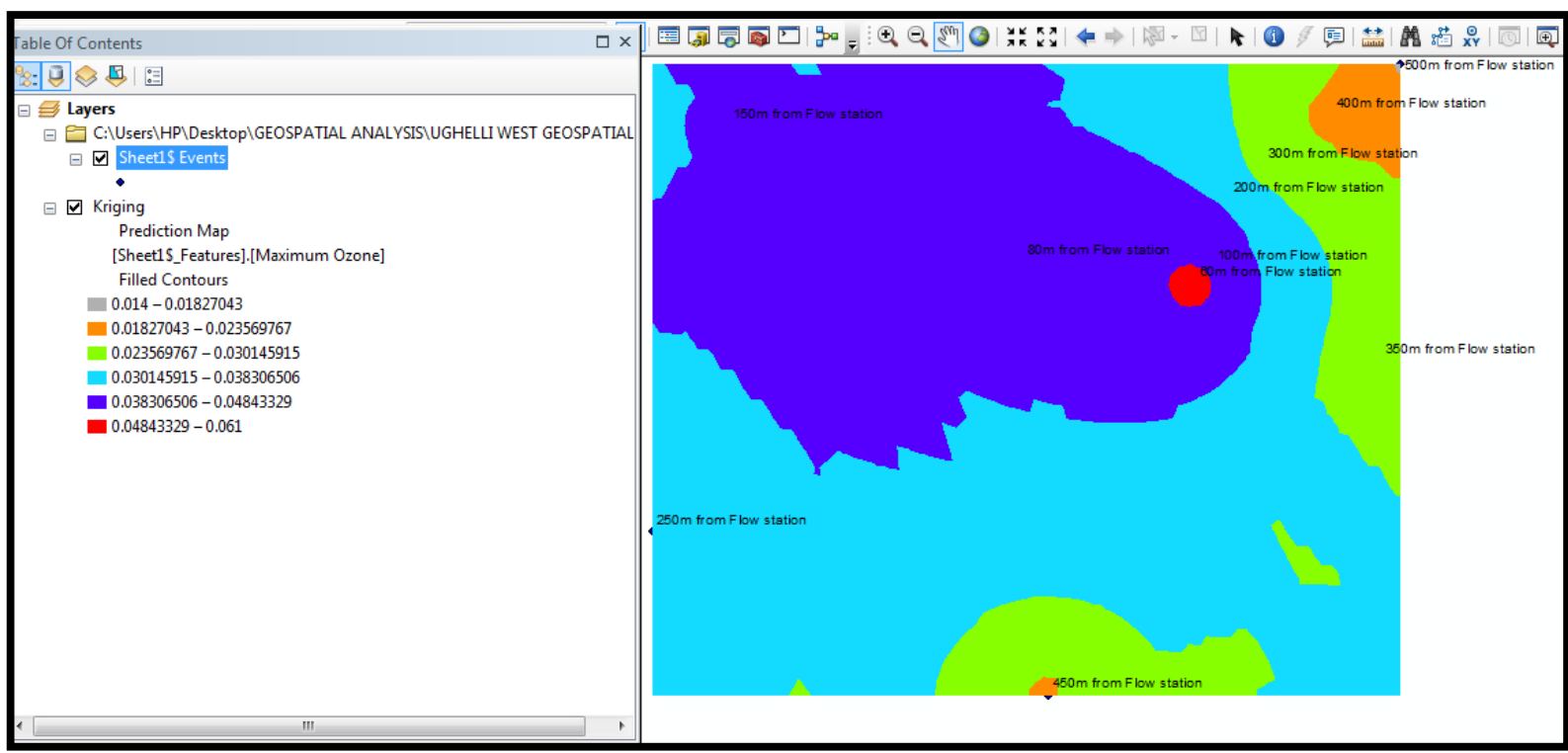

Figure 9: Prediction map for spatial distribution of ozone around Ughelli West flow station

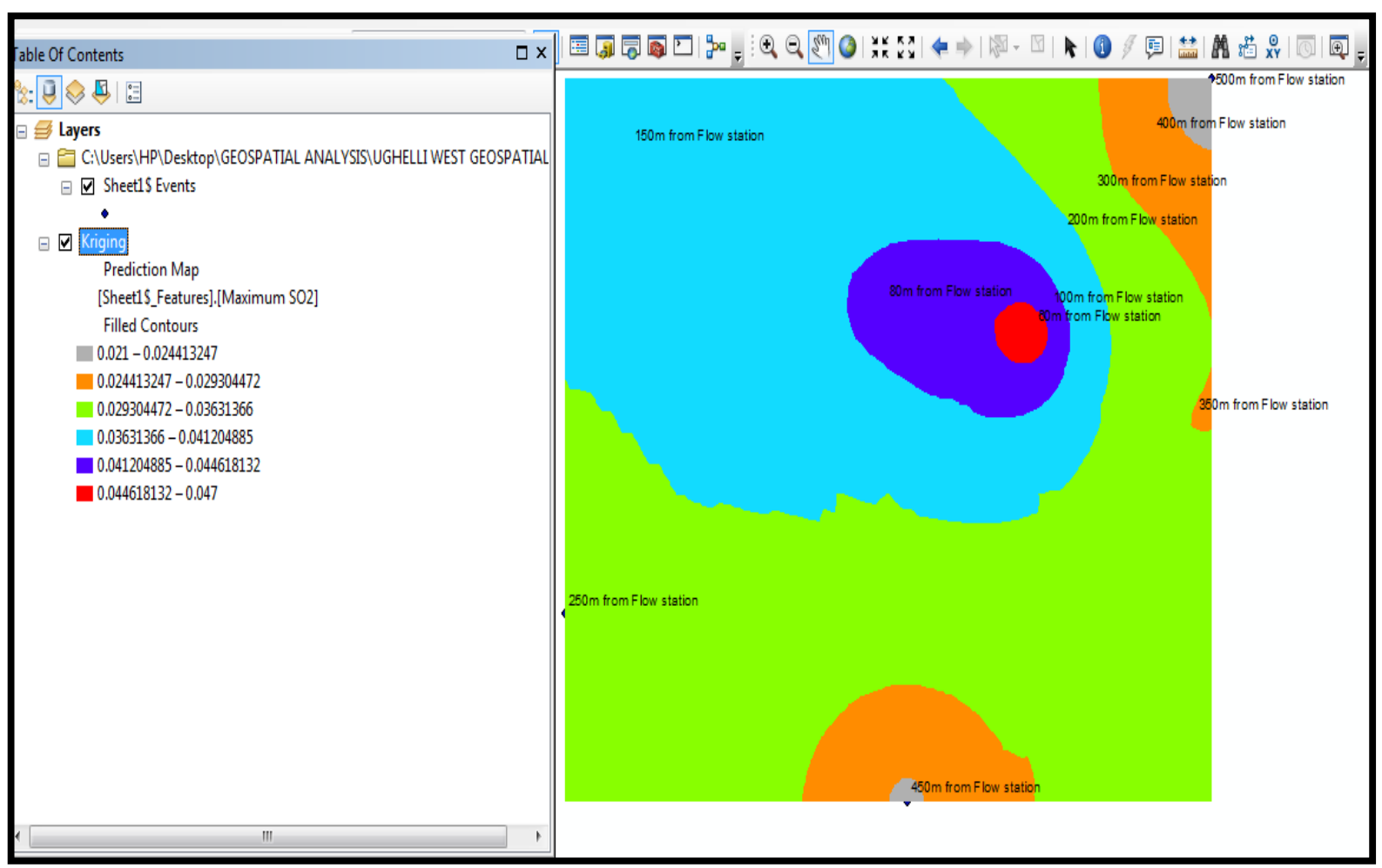

Figure 10: Prediction map for spatial distribution of sulphur (iv) oxide around Ughelli West Flow station

\subsection{Conclusion}

The geostatistical modelling and mapping of the level of concentration of gaseous pollutants around Ughelli West gas plant and flow station located at OML 34 of Delta State of Nigeria was carried out. Five gaseous pollutants, which were examined in the study area and their concentration determined, include VOCs, $\mathrm{CH}_{4}, \mathrm{NO}_{2}, \mathrm{SO}_{2}$ and $\mathrm{O}_{3}$. The results obatined from the diagnostic statistics for the ozone and around sulphur (iv) oxide around Ughelli West flow station show the reliability of the predicted values, since a smaller root mean square, and a standard root mean square closer to one(1) were obtained. The prediction maps do not only showed areas with lower pollutants concentrations which can be utilized for urban/town planning but also showed that from a distance of $400 \mathrm{~m}$ and above the pollutants concentrations will experience reduction. The prediction maps are useful in the planning of residential areas since they provide relevant information about the spatial concentrations of gaseous pollutants in the study area. 


\section{References}

Ajugwo, A.O. (2013). Negative effects of gas flaring. The Nigerian Experience. Journal of Environment, Pollution and Human Health, 1, pp. 6-8.

Akpoborie, I. A., Ekakite, A.O. and Adaikpoh, E. O. (2000). The Quality of Groundwater from Dug wells in parts of the Western Niger Delta. Knowledge Review, 2, pp. 72-79.

Anjaneyuhu, Y., Venkata, B.R.D. and Sudha, Y. (2011). Air Pollution, Modeling and GIS based Decision Support Systems for Air Quality Risk Assessment. ISBN: 978-953-307-511.2. In Tech, http://www.intechopen.com/books/advanced - Air -pollution/ air - pollution modelling - and - GIS

Bailey, T.C. and Gatrell, A.C. (1995). Interactive Spatial Data Analysis. Longman Scientific and Technical, Harlow, England.

Carleton, T.A. and Hsiang, S.M. (2016). Social and economic impacts of Climate. Science, 353. http://dio.org/10.1126/science.aad9837.

Chang, K. (2014). Introduction to Geographic Information Systems. $7^{\text {th }}$ Edition, McGraw-Hill Companies, Inc. 425pp.

Clark, P.U., Shakun, J.D., Marcott, S.A., Mix, A.C., Eby, M., Kulp, S., et al. (2016). Los Angeles megacity: a high resolution land-atmosphere modelling system for urban $\mathrm{CO}_{2}$ emissions. Atmos. Chem Phys, 16, pp. 9019-9045.

Davis, J.C. (1986). Statistics and Data Analysis in Geology. $2^{\text {nd }}$ Edition, Wiley, New York.

EGASPIN (2002). Environmental Guidelines and Standards for the Petroleum Industry in Nigeria, Revised Edition.

Environmental System Research Institute (ESRI), Manual on ArcGIS, ESRI Inc. Press, Redland, New York, California, USA.

Ismail, O.S. and Umuokoro, G.E. (2012). Global Impact of Gas Flaring. Energy and Power Engineering, 4, pp. 290-302.

Ite, A. E. and Udo, J. I. (2013). Gas flaring and venting associated with petroleum exploration and production in the Nigeria's Niger Delta. American Journal of Environmental Protection, 1(4), pp. 7077.

Jarvis, C. H., Stuart, N. and Cooper, W. (2003). Infometric and Statistical Diagnostics to provide Artificially- Intelligent Support for Spatial Analysis: the example of Interpolation. International Journal of Geographical Information Science, 17, pp. 495-516.

Khitoliya, R.K. (2007). Environmental Pollution. Management \& Control for Sustainable Development. Revised Edition, S. Chand \& Company Ltd. Ram Nagar, New Delhi.

Lelieveld, J., Evans, J.S., Fnais, M., Glannadaki, D. and Pozzer, A. (2015). The contribution of outdoor air pollution sources to premature mortality on a global scale. Nature, 525, pp. 367-371.

McCormac, J. (2004). Surveying. $5^{\text {th }}$ Edition, John Wiley and son, USA.

Narayanan, P. (2009). Environmental Pollution: Principles, Analysis and control. CBS Publishers and Distributors PVT. Ltd. New Delhi. Reprint.

Obahiagbon, K. (2002). Air Pollution. Hand book on Environmental Pollution. Edited by A.O. Ibhadode, Faculty of Engineering, University of Benin, Nigeria. 206 pp. 
Odjugo, P.A.O. and Osenwemkhae, E.J. (2009). Natural Gas flaring affects Micro-Climates and Reduces Mize (Zeamays) yield. International Journal of Agriculture and Biology, pp. 408-412.

Oghifo, O.T. (2011). Gas flaring / Power Plant in Nigeria. Social, Economy and Environmental Impact on the People of Niger Delta.

Olabaniyi, S. B. and Efe, S.I. (2007). Comparative assessment of rainwater and groundwater quality in an oil producing area of Nigeria. Environmental Health and Res., 6(2), pp. 111-118.

Orubu, C. O. (2002). Oil Industry activities, environmental quality, and the paradox of poverty in Niger Delta, pp. 17-31.

Rai, R., Rajput, M., Agrawal, M, and Angrawal, S. B (2011). Gaseous Air pollutant: a Review on Current and Future Trends of Emissions and Impact on Agriculture. Journals of Scientific Research Banaras Hindu University, 55, pp. 77-102.

SHELL Petroleum Development Company (SPDC) (2000). SHELL Petroleum Development Company of Nigeria.

Webster, R. and Oliver, M.A. (2001). Geostatistics for Environmental Scientists. Chichester, Wiley, England.

Yannawar, V., Bhosle, A. and Yannawar, S. (2014). Prediction of air pollution concentration using a fixed box model. 6(5), pp. 89-92. ISSN:1553 -9865, http://www.sciencepub.net/researcher.

Zhang, K., Chen, S.C., Whitman, D., Shyu, M.L., Yan, J. and Zhang, C. (2003). A progressive morphological filter for removing non-ground measurement from airborne LIDAR data. IEEE Transaction on Geoscience and Remote Sensing, 41, pp. 872-882. 